\title{
Training Mode Innovation Research of Human Resource Professionals Internationalization in China
}

\author{
Jin-han ZHOU ${ }^{1, a,{ }^{*}}$ and Hao-yu HUANG ${ }^{1 . b}$ \\ ${ }^{1}$ Wuhan UnivTechnol, Sch Management, Wuhan 430070, People R China \\ a2293434516@qq.com, b757995713@qq.com
}

\begin{abstract}
Keywords: Human Resource Professional, Internationalization of Talents, Training Mode Innovation.
\end{abstract}

\begin{abstract}
With the development of economic globalization, not only a variety of specialized internationalized talents are needed, but also those with international vision, able to cope with the international challenge of human management internationalization, while the existing training mode can't meet the market demand. Therefore, the establishment of the advancing internationalization of human resource management professionals training mode has become a problem to be solved. Based on this, we put forward "ecotype" international human resources professional personnel training mode containing cultivating way, cultivation system, curriculum system and teachers, to speed up the internationalization of human resource professional talent training in colleges.
\end{abstract}

\section{Introduction}

Since the 1990s, with astonishing speed development of science and technology, especially High-tech following information technology revolution, it broke through national boundaries, and gradually formed the economic globalization. However, economic globalization is a "double-edged sword". On the one hand, it can promote the development of global productivity, and accelerate world economic growth. On the other hand, it also will increase the international competition, increased international risk [1].

In fact, for the human resources professional settings in our country starting relatively late, human resources professionals able to adapt to the challenges of globalization of international human resource management is still obviously insufficient. Its main reason is that colleges do not have an international personnel training mode targeting human resources professional. Studies show that human resource professional personnel training mode currently used in the collage most apply mechanically with other professions, but considering the professional and particularity of human resource management, the traditional human resources professional personnel training mode is difficult to meet the demand of economic globalization. Therefore, innovation of the university human resources professionals training mode innovation is imminent.

This paper is to analysis the status quo of human resource professional personnel training mode in university, point out its problems in internationalization and the causes of these problems, and then put forward comprehensive training mode innovation to provide theoretical reference and decision-making advice for the internationalization of university human resources professionals. 


\section{"Ecotype" Training Mode}

Aiming at the problems existing in the current international human resources professional, we put forward the "ecological" internationalization of human resource training mode including cultivating mode, training system, curriculum system and faculty four aspects from the perspective of education mode. The cultivating way mainly include international communication and academic research, etc; Training system includes studying and teaching management mode and the corresponding policy of universities and government; Curriculum system is mainly the curriculum, course content and teaching method, etc.; While teachers refers to the ability to participate in international teaching teachers. These four aspects together form an organic "ecotype" internationalized talents training mode, continuously producing a large number of excellent human resources management internationalization talents.As shown in the figure1.

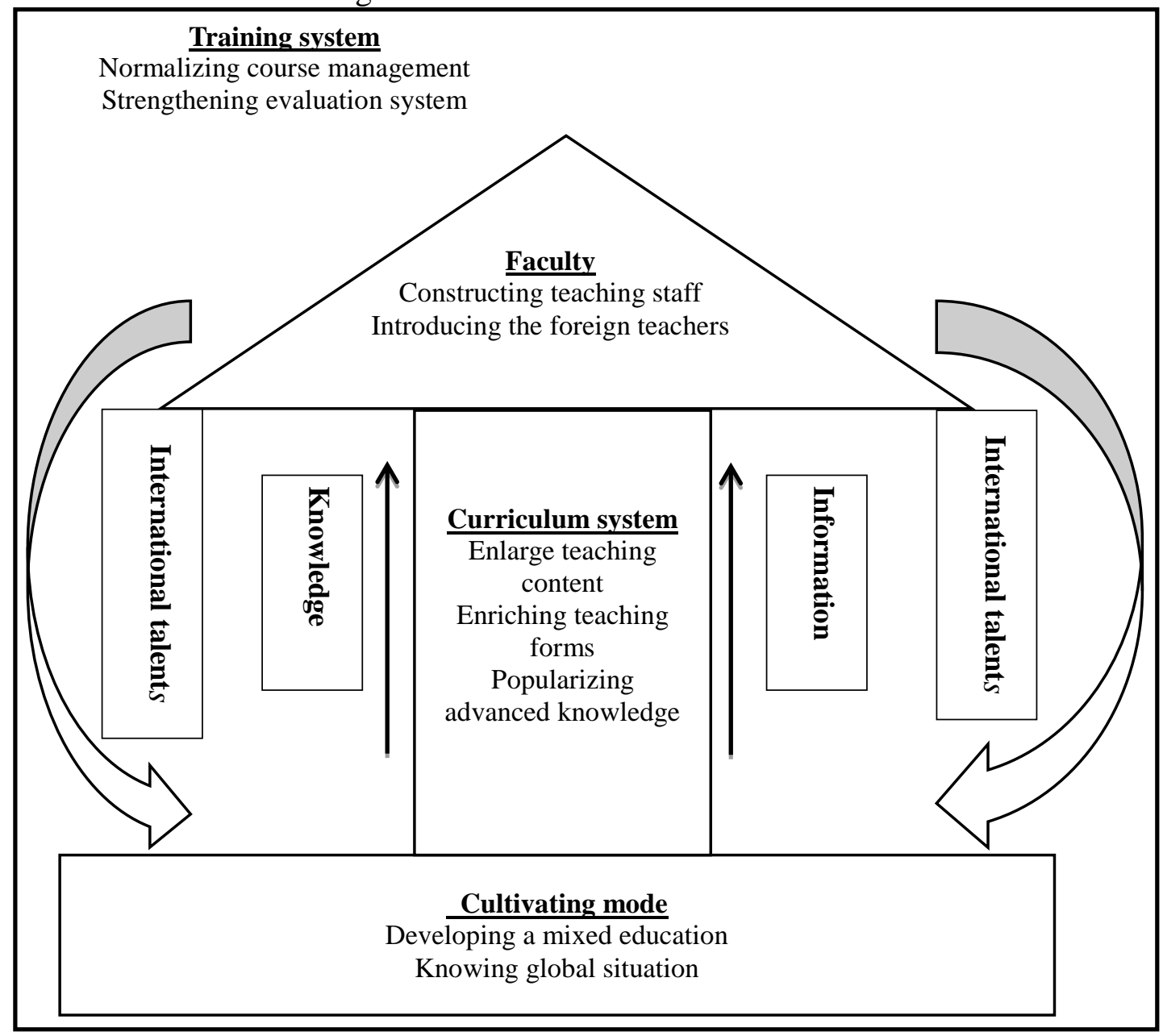

Figure 1 "Ecotype" training mode of internationalization talents training

Note:

Environment_Cultivating system (Providing good environment)

Trunk_Curriculum system (Conveying information)

Branches and leaves_-Faculty (Undertaking talents education)

Soil_Cultivating mode (Providing resource platform)

Water_-Knowledge

Air_-information

Fruit_—-Internationalized talents 
Among them, the training system provides a good living environment for the whole training mode, only in the specification, fair institutional environment can all kinds of training mode and curriculum system work effectively, and then maximize training effectiveness. Cultivating mode is the soil of the training mode, providing the platform and resources for internationalization of talents training, collecting a lot of knowledge and information in the cultivation of the diversification and modernization way; Curriculum system is the trunk of the training mode, conveying knowledge and information in the form of teaching for internationalized talents; Faculty is the branches of whole training mode, undertaking specific talent education task. Various training modes need teachers and scholars to shape the talent eventually by precept. The final fruit namely is the internationalized talents of the cultivation model.

In addition, the training mode is a virtuous cycle system. Internationalized talents cultivated by good enough teachers can continue supplementing the faculty, also can enrich the existing form of cultivating mode by participating in international communication and cooperation, providing more internationalized resource for internationalization of talents training, so as to promote the next round of cycle. When the whole training mode is in the process of a virtuous cycle, it can produce a steady stream of international talents to help our country to obtain a better position in the international competition.

\section{Supporting Measures of "Ecological" Training Mode}

\section{Training Way of Keeping the Pace with the Times}

Existing international training modes mainly include international conference, cooperation in running schools, students, etc., which provide communication platform and teaching resources for internationalization of talents training, and gather all kinds of knowledge and information [2]. However, as the changes of the times, colleges and universities must focus on the development trend and requirements of human resource management, and adjust the cultivation of the internationalization of talents training target and way according to the development trend of change. Only by truly advancing with the times and continuous innovation can we meet the changing needs of talent market.

Developing a Mixed Education. Human resources professional talents internationalization can't leave without the personnel exchanges between countries, for that the exchange of knowledge and information must be by artificial medium. Whether domestic students to study abroad or to attract foreign talents exchange to come to China is the important way to promote international understanding. Therefore, the advantage of rapid economic development in our country should be used to develop the mixed education of colleges and universities.

Knowing Global Situation. The human resources professional is a practical major, and closely related with the development of society and economy. Therefore, as students in human resources, it is very important to understand the current market situation of human resources [3]. In the teaching process, teachers should emphasize the importance of attention to current events to all students, guide students to focus on global human resources market supply and demand situation, especially various professional talents demand of the world top 500 enterprises. 


\section{Scientific and Reasonable Cultivation System}

Strict training system can provide a good environment for talents cultivation internationalization, and help the talents training mode to operate effectively. In the current training mode, the universities and the government has put forward a series of preferential policies for the development of education. In terms of teaching, universities have also been equipped with more adequate teaching facilities. But it is seriously insufficient for the internationalization course management and academic achievement evaluation, which still need to be further improved.

Normalizing Course Management. Curriculum management standardization is the important guarantee to improve the quality of teaching, perfect evaluation system should be established to achieve this standard. Colleges and universities should put in more manpower and material resources to work out the curriculum standards and the evaluation of the course [4]. By following the internationalized level and combining the present situation of our college, we can develop a set of standardized curriculum standard. Special evaluation team should be set up in colleges and universities to effectively evaluate and feedback the design and implementation of internationalized curriculum, to ensure that the existing internationalization course really reach the international standard and play a role of the internationalization of education.

Strengthening Evaluation System. Internationalization of talents training not only needs to provide students with a good teaching environment and adequate financial supports, but also should be equipped with strict appraisal system. First of all, students participating in the competition must be selected strictly when determining communication list. Second, in the process of studying abroad, the colleges should keep long-term contact with students abroad. Finally, at the end of the communication, the college must audit on their academic achievements strictly, confirming owning full credits and scientific research. Only by "strict in, strict out" can we guarantee the effective implementation of training plan.

\section{Rich Curriculum System}

Enlarging Teaching Content. It is known that the existing professional course of international human resources is relatively monotonous. Most colleges and universities only set up professional English courses, not only leading to the lack of professionalism and pertinence, also not conducive to cultivate the internationalized professional thinking[5].Therefore, colleges and universities should set up rich international professional courses, such as the courses about job interviews, business communication and professional foreign language writing.

Enriching Teaching Forms. In view of the existing problem, two aspects may be innovated as following:

"Hybrid" Teaching. In the professor internationalization course, international students and domestic students can be arranged to have class together, which will strengthen exchanges about study method on both sides. The internationalization course teaching should not only contain the internationalization of the teaching content, but also international approach to learning, "hybrid" teaching can provide the opportunity effectively.

Classroom Interaction. As a way to train internationalized talents, internationalization course should emphasis the classroom interaction, promoting the students' independent thinking and autonomous learning ability. The process can enhance the students' ability of autonomous learning and access to information, and build the international thinking and consciousness, which helps achieve the goal of education internationalization. 
Popularizing Advanced Knowledge. As various changes of the global politics, economy, culture and other external environment, the development status of each subject has been changed, as a member of management, the research results and the rules of human resource management especially change at an alarming rate every year. To realize the internationalization of talents and keep up with the pace of the times, we must popularize the forefront knowledge of human resource profession, such as SA8000 international standard, in the process of teaching, which help students know the development degree of human resources profession and guide the direction of their learning.

\section{Excellent Faculty}

Constructing Teaching Staff. In the era of knowledge economy, talent is the core of the era, so the teachers who impart knowledge play a key role in the process of talent training. Similarly, the internationalization of human resource management also depends on excellent faculty. In order to produce teachers meeting the requirements, colleges should strengthen financial and policy support to create a good training environment. What's more, they need to increase the chance of teachers to study abroad to cultivate backbone teachers with overseas study and teaching experience.

Introducing the Foreign Teachers. In addition to develop domestic teachers, introduction of foreign teachers is amore direct and efficient way to constructing teachers. Foreign teachers have unique teaching ability as well as international teaching thought and concept that many domestic teachers cannot match. Employing excellent foreign teachers not only can improve the students' language ability and application ability, but also help the students learn more cutting-edge knowledge in human resources. At the same time, the pure English teaching can also can improve students' ability to write academic papers in English, conducive to publishing core journal articles.

\section{Conclusion}

This article points out various problems existing in the current training mode through the concrete analysis of present internationalization talents training of human resource management, and then puts forward a "ecological" internationalization training mode, which can cultivate a large number of internationalized talents through a virtuous cycle system. Based on the current situation, we put forward a series of targeted improvement measures, aiming to provide more ideas of the internationalization of human resource management, and add a motivation for the internationalization of talent.

\section{Acknowledgement}

This research was financially supported by the National Social Science Foundation (14BGL200) and Teaching Research Fund Projectw2014034). 


\section{References}

[1] H. Xu, H.P Teng. Internationalized talents cultivation research of business administration profession of university [J]. Journal of human resource management, 2011 (11): 146-147

[2] C.W Hong, The history study of development of American graduate education [J]. Journal of degree and graduate education, 2002 (2-3): 68-73.

[3] Y.Q Zhou. The speech for the first national ordinary university teaching work conference [J]. Journal of higher education research, 1998(3).

[4] L.L Hu. Training mode research of university graduate student in China-from single to dual mode [D]. East China normal university, 2004.

[5] H. Cao, Z.H Guo. Choice of human resources management professional English teaching materials research [J]. Modern commercial and trade industry, 2009, 21 (14): 178-179. 